\title{
BREAKDOWN OF THE IMPELLER WHEEL OF A TG2 KAPLAN TURBINE
}

The paper deals with the investigation of the breakdown of the impeller wheel of a TG2 Kaplan turbine with the power of 36 MW that was operating for only 6.5 years. To find the cause, both methods of investigation of mechanical properties and analyses of microstructure and micrographics were used. On the basis of the results of individual analyses we found out that the primary cause of the impeller wheel breakdown was inconvenient material of the servomotor rod.

\section{Introduction}

Nowadays, Slovak hydro-electric power plants present a significant source of energy. Beside the fact that they belong to renewable resources, they serve as peak power plants. Regarding their important function in electric power production and relatively high installation costs, they are constructed in order to feature a long operating life. However, in some exceptional cases a failure in part of the energy chain may occur. Breakdowns of the impeller wheel of a turbine are particularly serious, as their dismantling is very complicated, time and money demanding and it can cause a failure of other parts of the power plant, or serious ecology damage.

The paper deals with breakdown of the impeller wheel of a Kaplan turbine. The nominal performance of the turbine is $36 \mathrm{MW}$. The damaged turbine signed as TG2 was operating from April 1998. Till its breakdown the turbine ran for 23557 hours. During the operation no extreme states were found. The failure occurred suddenly on the servomotor of the impeller wheel that provided speed and performance regulation. At the breakdown oil from the hydraulic circuit of the servomotor penetrated into the area of the generator. After detecting the failure, the turbine was safely shut down in compliance with the standards.

The servomotor is placed in the middle of the impeller wheel and it is composed of the rod, piston, cylinder, tail mechanisms and hydraulic distribution. The rod together with the piston are firmly joined to the body of the impeller wheel. The cylinder is doubleacting and with the help of the tail mechanisms it provides the turbine with vanes coiling. When the secondary regulation is engaged in operation, the servomotor can get a signal to switch the vanes in $15 \mathrm{~s}$ periods. When the servomotor fails, the turbine loses the possibility of regulation and there is threat of the machine collapse. Regarding the servomotor placing, it was necessary to dismantle the regulator, generator, impeller wheel and also the turbine chamber.

\section{Experimental part}

To find the reasons of the breakdown, the following procedures were chosen: dismantling of the hydraulic circuit, dismantling of the generator rotor, extraction of the impeller wheel, dismantling of the servomotor, visual checking of the whole wheel and finally, the analysis of the damaged part material.

Basic operational parameters of the impeller wheel:

Number of operation hours

Speed frequency

Number of revolutions to failure

Impulse of secondary regulation

Number of servomotor throws

Area of piston

Pressure of servomotor oil

Maximum force from piston

Rod material

Weight of piston

Piston material

Weight of rod

Nominal stress in rod

Weight of cylinder

\section{Visual checking}

After extracting the turbine impeller wheel from the chamber and dismantling its bottom it was found out that the rod of the servomotor was extruded downwards by about $4.2 \mathrm{~cm}$ (Fig. 1). On its upper part it can be seen that there is a fracture of the whole rod cross-section just under its flange (Fig. 2). The fracture has a fatigue character in the constitutive part of its cross-section (Fig. 3), while the initiation of the fracture was from the gasket and slot from

\footnotetext{
* Peter Palček, Mária Chalupová

Department of Materials Engineering, Faculty of Mechanical Engineering, University of Žilina, E-mail: peter.palcek@fstroj.utc.sk
} 


\section{KOMNIKCOCle}

various parts over the whole perimeter of the crossing area. The parts of the damaged gasket (Fig. 4) and forged pieces of metal

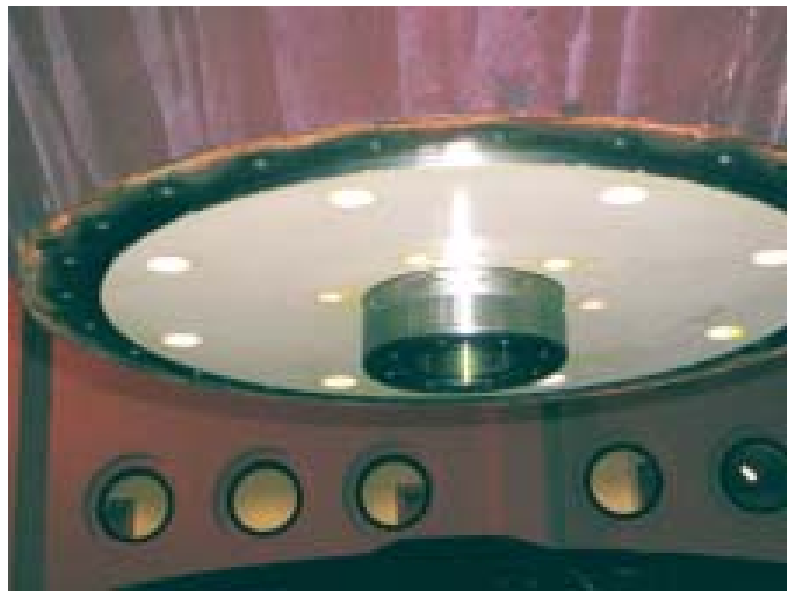

Fig. 1 The rod extrusion from bottom bearing

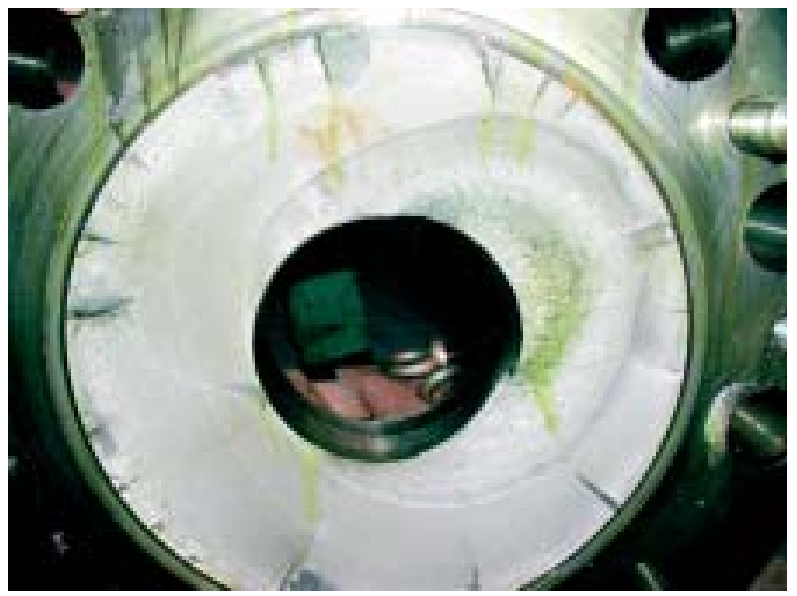

Fig. 3 The fracture of the rod

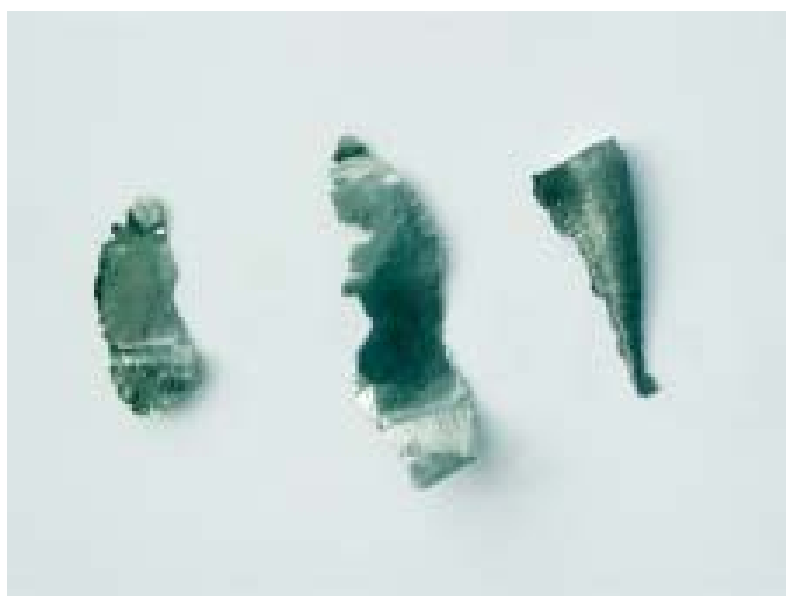

Fig. 5 Forged pieces of the rod caused by the crack growth were on the surface of the fracture. The thickness of these pieces ranged from 5 to $14 \mu \mathrm{m}$ (Fig. 5).

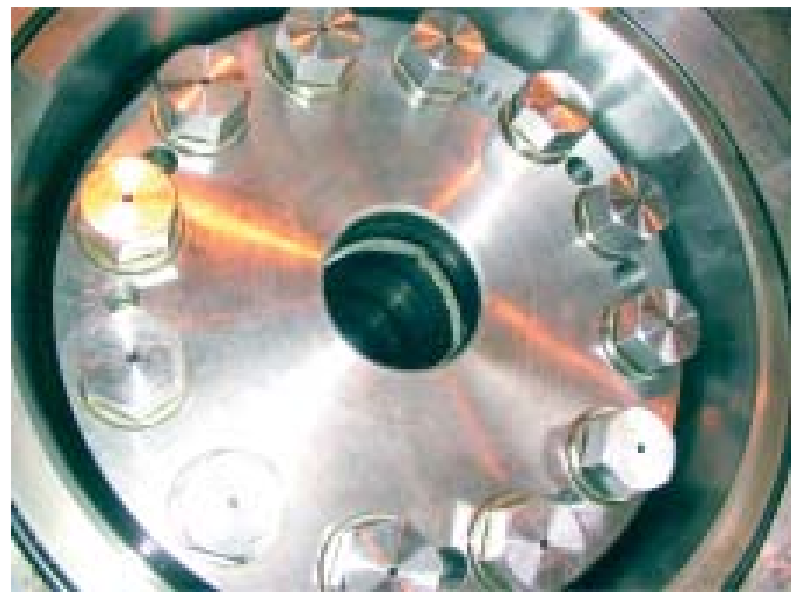

Fig. 2 The fracture of the rod under its flange

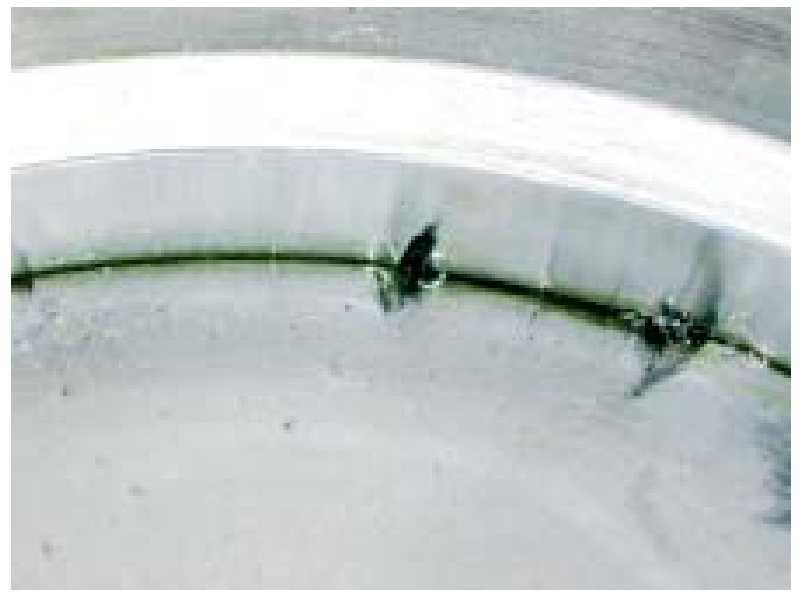

Fig. 4 The parts of gasket between the rod and the body of the turbine rotor

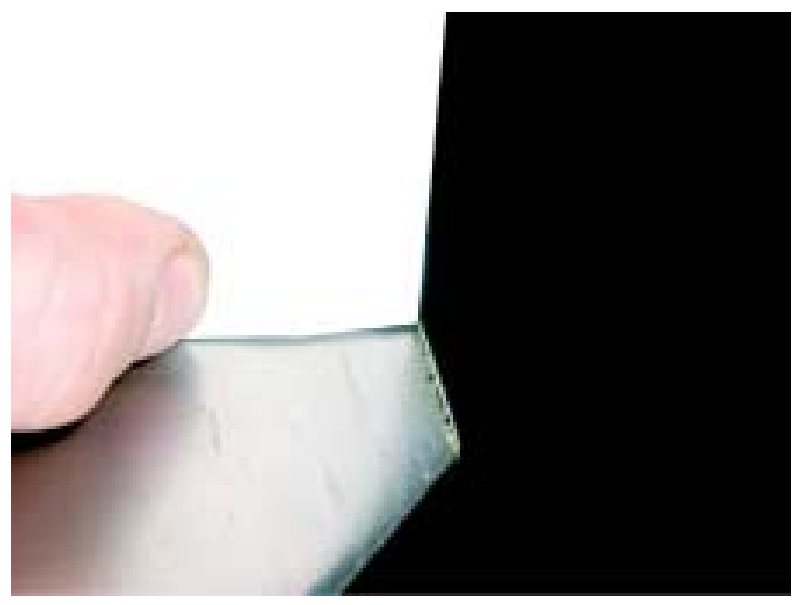

Fig. 6 Extruded material on the edge of the vane 


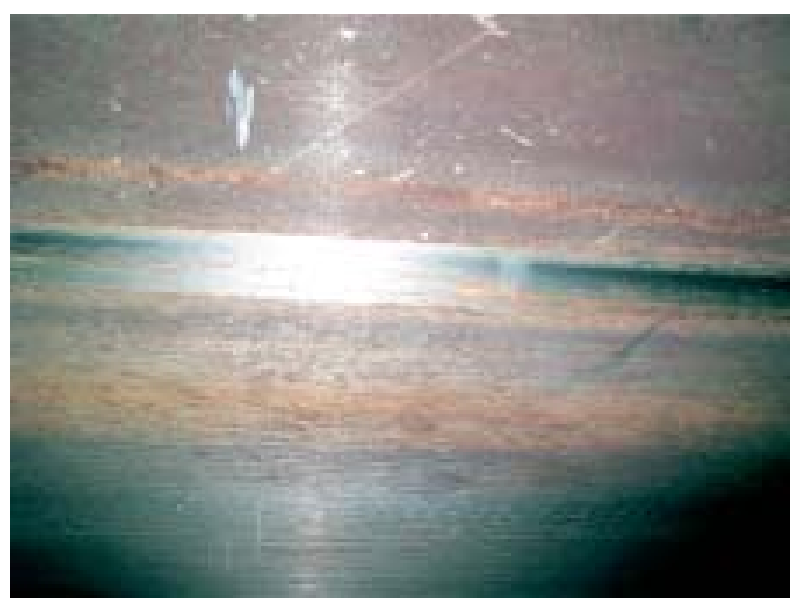

Fig. 7 The failure of the chamber surface of the turbine by wear from vanes

By inspecting the impeller wheel we found out that there are areas without biological corrosion on the external circumference of the vanes. It means that the vanes had a direct contact with the turbine chamber when moving. This presumption is confirmed by the extrusion of material on the whole circumference of the vanes (Fig. 6) and by a continuous glossy track created by a mechanic contact with the vanes (Fig. 7).

By dismantling the servomotor cylinder it was found out that there is a crack on the piston. The crack is growing in the direction to the external diameter approximately to the two thirds of the diameter (Fig. 8). On the crack tip it is visible that the material of the piston is plastic (Fig. 9). This is typical for crack growing. On the contact area of the matrix that secures the position of the piston on the rod and transmits the forces from the piston to the rod,

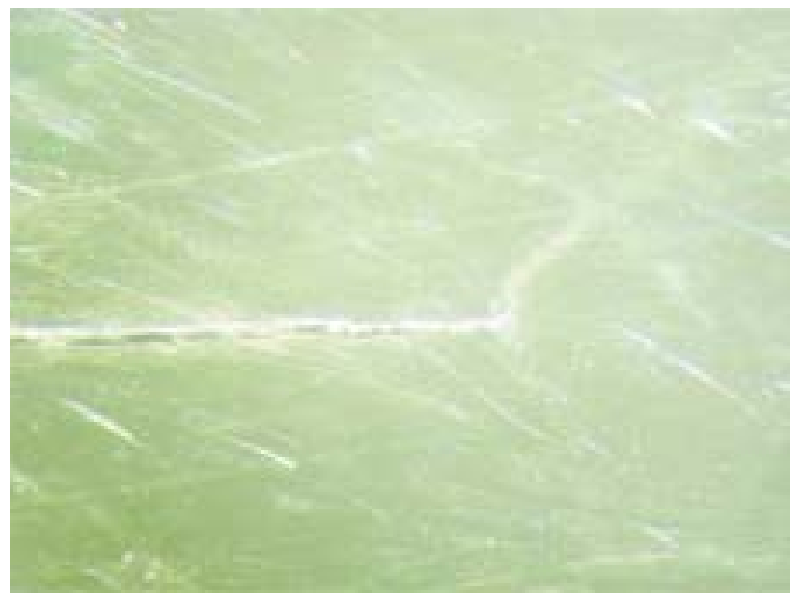

Fig. 9 The detail of the crack end on the piston

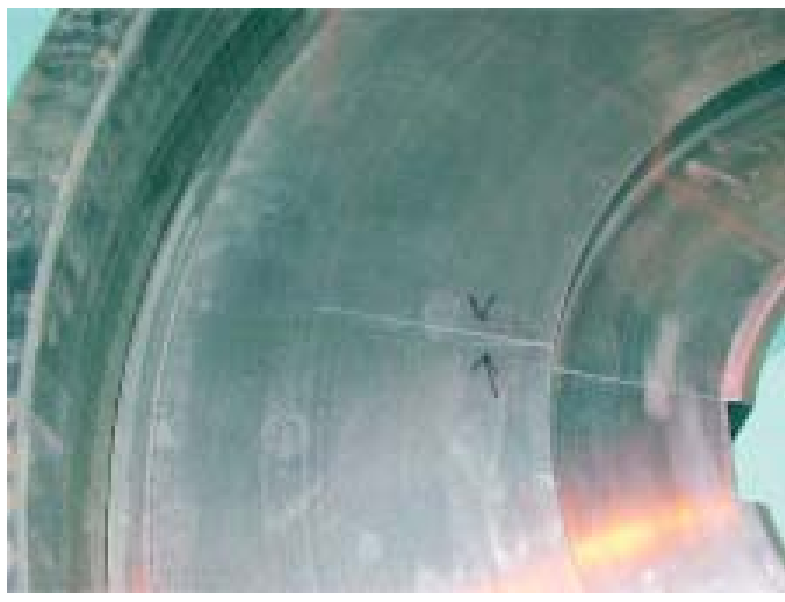

Fig. 8 The crack in the piston of the servomotor

the maps with a changed surface quality were found out (Fig. 10). It is typical for contact fatigue.

After complete dismantling of the impeller wheel it was found out that the rod is damaged by longitudinal lines and there is a large failure by contact fatigue - pitting (Figs. 11 and 12) on the functional areas of the rod.

On the basis of the visual checking and positive findings it was possible to state that the fatigue failure of the rod affects more than $85 \%$ of the supporting cross-section and the fatigue fracture was initiated at various places on the rod circumferences. Mechanic contact of the vanes with the turbine chamber verifies disalignment of the impeller wheel with the bearings or it means that there was an ample allowance in the main bearing. Contact fatigue on the

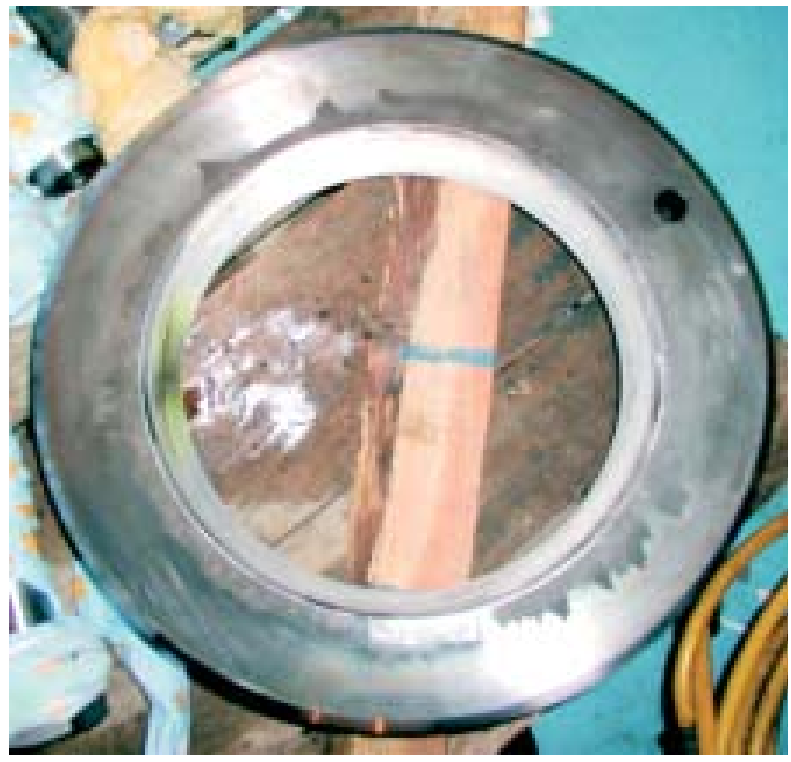

Fig. 10 Pressing of the matrix surface 


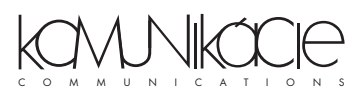

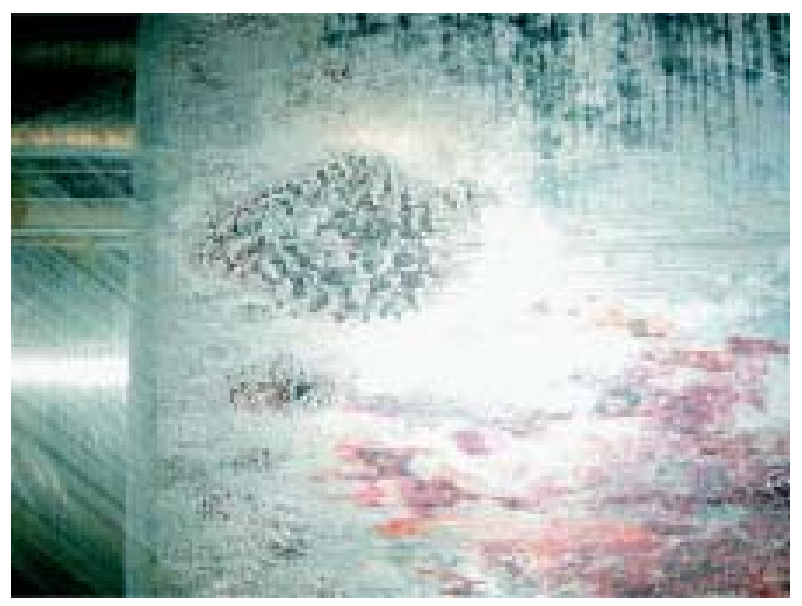

Fig. 11 Deep pittings on the functional surface of the rod

functional areas of the rod and impeller wheel proves that the rod has a relatively big side oscillation that caused contact wearing and contributed to the total fracture of the rod. The side oscillation operated as an additional tension (bending) and it was superimposed on the longitudinal tension from the piston. The oscillation could be caused by asymmetry of the loading from the piston or by the impact of centripetal forces caused by oscillation of the whole impeller wheel.

The failure of the piston by the crack could be caused by concentration of tensions in the slot for spring, by a directed structure after rolling or by a structural non-homogeneity of the piston material. The contact fatigue on the rod matrix verifies a mutual micro motion between the piston and matrix (pulsating tension) that could contribute to the origin of additional loading of the piston.

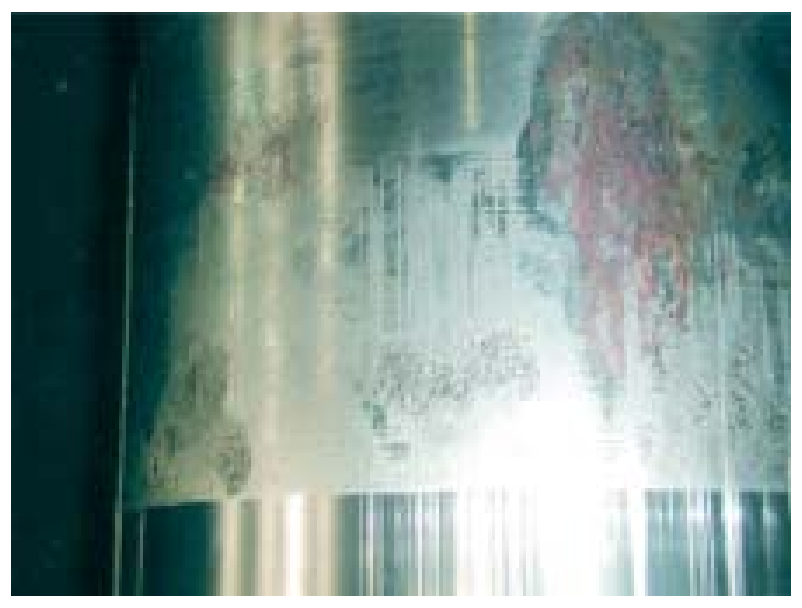

Fig. 12 Deep and shallow pittings on the functional surface of the rod

\section{Analysis of chemical composition}

According to the design documentation rod was produced by forging from StE 500 material and the piston was produced by hot rolling from St 52-3N material. The specimens extracted from the failed flange of the rod were used for the chemical analysis. The chemical composition of the rod according to the norm according to the certification of a supplier and according to the results of the chemical analysis is shown in Tab. 1

The results of the given analyses show that the chemical composition of the rod corresponds to the norm for StE 500 material with an exception - the content of copper. Copper as a pearlite creating element increases air-corrosion resistance and in the listed content, it should not affect mechanical properties significantly.

Chemical composition of the rod according to the norm and according to the certification

Tab. 1

\begin{tabular}{|c|c|c|c|c|c|c|c|c|c|c|}
\hline [wt \%] & $\mathrm{C}$ & $\mathrm{Mn}$ & $\mathrm{Si}$ & $\mathrm{P}$ & $\mathrm{S}$ & $\mathrm{Cr}$ & $\mathrm{Ni}$ & $\mathrm{Mo}$ & $\mathrm{Al}$ & $\mathrm{Cu}$ \\
\hline StE500 & 0.21 & $1.0-1.70$ & $0.16-0.60$ & 0.035 & 0.03 & 0.3 & 1.00 & 0.1 & 0.02 & 0.20 \\
\hline Certificate & 0.190 & 1.13 & 0.25 & 0.011 & 0.010 & 0.05 & 0.08 & 0.01 & 0.025 & 0.20 \\
\hline Positive & 0.225 & 1.235 & 0.255 & 0.013 & 0.0085 & 0.045 & 0.07 & 0.0095 & 0.018 & 0.235 \\
\hline
\end{tabular}

\section{Analysis of the material of the damaged part}

It was necessary to find out whether there had not been any substitution for material to find the reason of the damage and failure of the rod and piston. According to the given agenda, the rod and the piston were produced from normal, low-carbon steels of standard quality.

These analyses were performed in the frame of the experimental part: chemical composition determination, investigation of mechanical properties, metallographic analysis and micrographic analysis. Despite the fact that the piston of the servomotor was also damaged, the paper deals only with the analysis of the damage and failure of the rod as the primary cause of the breakdown.

\section{Mechanical properties}

Fundamental mechanical properties of StE 500 steel

Tab. 2

\begin{tabular}{|c|c|c|c|c|c|}
\hline Property & $\begin{array}{c}\mathrm{Re} \\
{[\mathrm{MPa}]}\end{array}$ & $\begin{array}{c}\mathrm{Rm} \\
{[\mathrm{MPa}]}\end{array}$ & $\begin{array}{c}\mathrm{A} \\
{[\%]}\end{array}$ & $\begin{array}{c}\mathrm{Z} \\
{[\%]}\end{array}$ & $\begin{array}{c}\text { Specimen } \\
\text { diameter } \\
{[\mathrm{mm}]}\end{array}$ \\
\hline StE 500 & 410 & $570-740$ & 17 & - & 10 \\
\hline Certificate & 438 & 587 & 28 & 57 & 10 \\
\hline
\end{tabular}

Mechanical properties of the rod material according to the norm for steel StE 500 and according to the supplied certificate are shown in Tab. 2. From the comparison of these parameters the 
material should correspond to the requirements of the norm and to the requirements for the loading intensity. Regarding the fact that the rod material has a ratio of $R m / \operatorname{Re}>1.4$, it was assumed that in the consequence of cyclic loading the hardness would be slightly increased. This assumption was not confirmed by the hardness and toughness tests.

At the evaluation of the rod material properties, the hardness of the material was the first property to be investigated. It was necessary to perform a tensile test (manufactured specimen had a diameter of $10 \mathrm{~mm}$ ) regarding the fact that hardness according to Brinel reached the maximum values HBS 2.5/62.5/10 = 136, this corresponds to the tensile strength of $470 \mathrm{MPa}$ and does not correspond to the values given in the norm. The recorded values are in Tab. 3.

Recorded tensile strength of rod material

Tab. 3

\begin{tabular}{|c|c|c|}
\hline Property & $\operatorname{Re}[\mathrm{MPa}]$ & $\operatorname{Rm}[\mathrm{MPa}]$ \\
\hline Specimen 1 & 318 & 484 \\
\hline Specimen 2 & 316 & 494 \\
\hline Specimen 3 & 315 & - \\
\hline
\end{tabular}

From the recorded values it is clear that the measured tensile strength is lower minimally by $100 \mathrm{MPa}$ than the one declared for rupture strength $\mathrm{Rm}$ and for yield stress $\mathrm{Re}$. It, therefore, means that the state of the rod material is unsatisfactory.

At the static tensile test, by gradual loading, it was found out that the cracks appeared on the surface of the tested rod. The cracks were just under the yield stress. These cracks could be observed without a microscope. Because of this, the surface of one tested

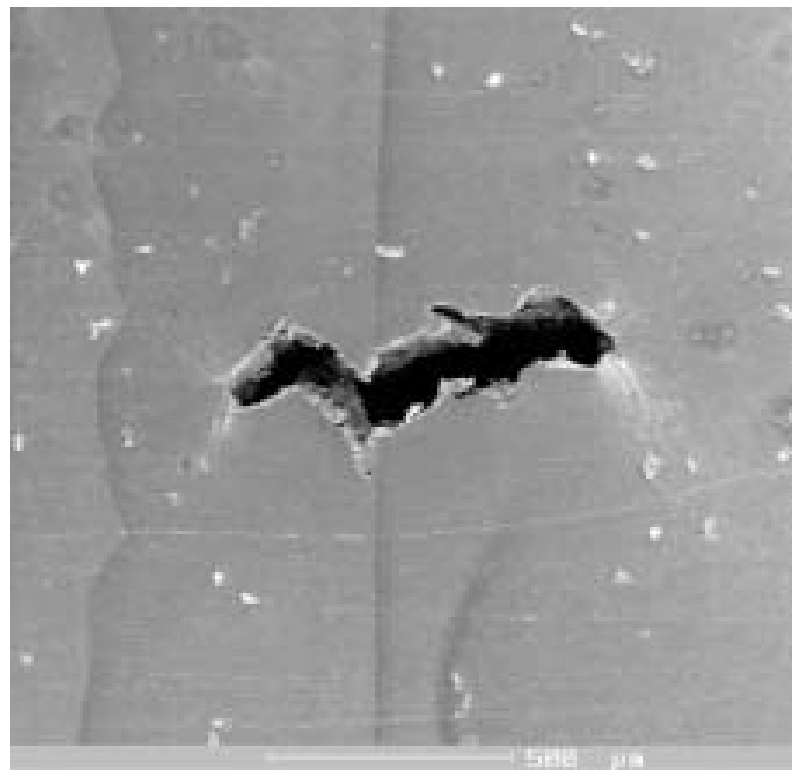

Fig. $13 \mathrm{~A}$ crack on the surface of the testing rod, REM rod (specimen 3) was polished and observed by a raster electron microscope after loading. The character of the failure is recorded in Figs. 13 to 16.

In the area of larger cracks (Figs. 13 and 14) a creation of slip lines - plastic deformation on the crack tip is observed. The creation of cracks is probably conditioned by presence of inclusions in the material structure. These inclusions are non-coherent and hard. They cracked by loading and they got separated from the basic material (Figs. 15 and 16) and it means that they served as micro cracks nuclei.

\section{Metallographic analysis}

The specimens for the metallographic analysis were extracted in a way to be characteristic for the microstructure of the steel in a vertical direction to the surface of the rod flange (cross-section) and in a parallel to the rod surface (longitudinal section). The specimens were prepared by standard metallographic methods. The microstructure was evaluated by an optic microscope NEOPHOT 32 (Figs. 17 and 18) and by an electron microscope TESLA BS 343 (Figs. 19 to 22).

Steel structure is irregular, ferritic-pearlitic, created by grains of different sizes. Pearlite is lamellar in many cases, but it also exists in a spheroidic shape that corresponds to soft annealing. The size of ferritic grains is also very different. Moreover, it exists in the shape of Widmannstätten structure in many cases. Spheroidic pearlite is created by soft annealing that is realized at heating of material just under $\mathrm{AC} 1$ and leaving it at this temperature for some hours. In the case of the evaluated rod, a partial spheroidization occurred by slow cooling of the rod after forging. On the other hand, ferrit in the shape of Widmannstätten structure is created by rapid cooling

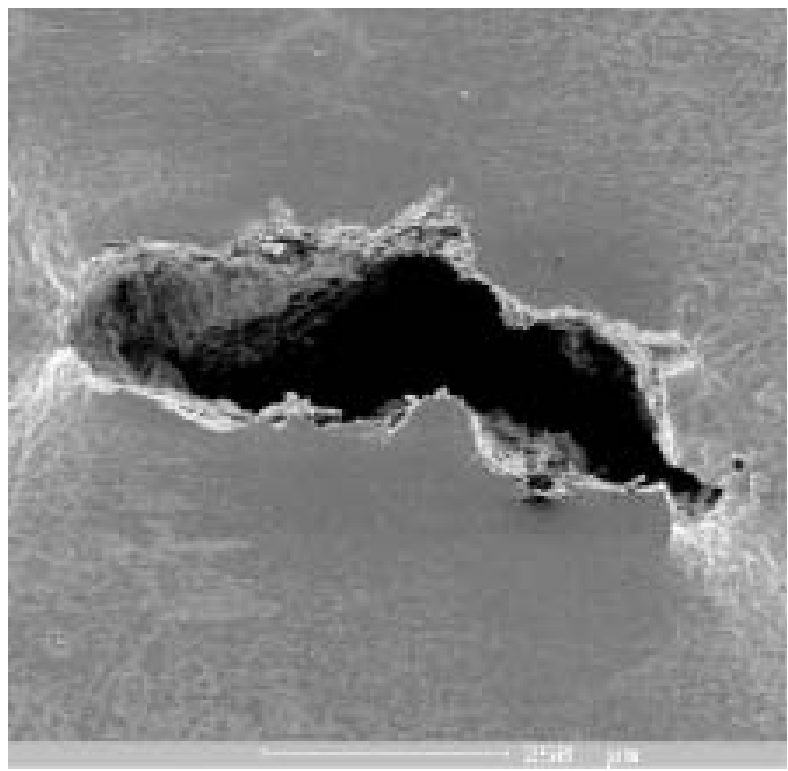

Fig. 14 A different crack, plastic deformation on the crack tip, REM 


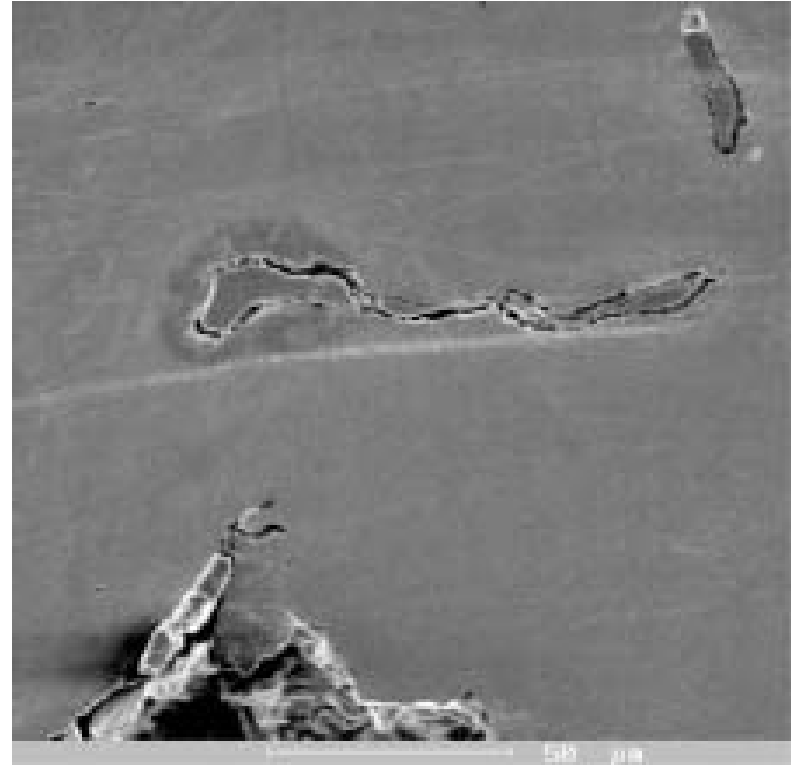

Fig. 15 The separation of an inclusion from basic material, REM

from high temperature that occurs at over-heating over permissible hardening temperatures. Both processes, i.e. over-heating over hardening temperatures as well as slow cooling contribute to the creation of irregular grain.

The electron microscope evaluation was focused on the documentation of the size and shape irregularity of the grains of ferrit and pearlite and on the evaluation of the shape and occurrence of inclusion in the structure. The REM evaluation confirmed that the structure of the material is ferritic-pearlitic, very irregular

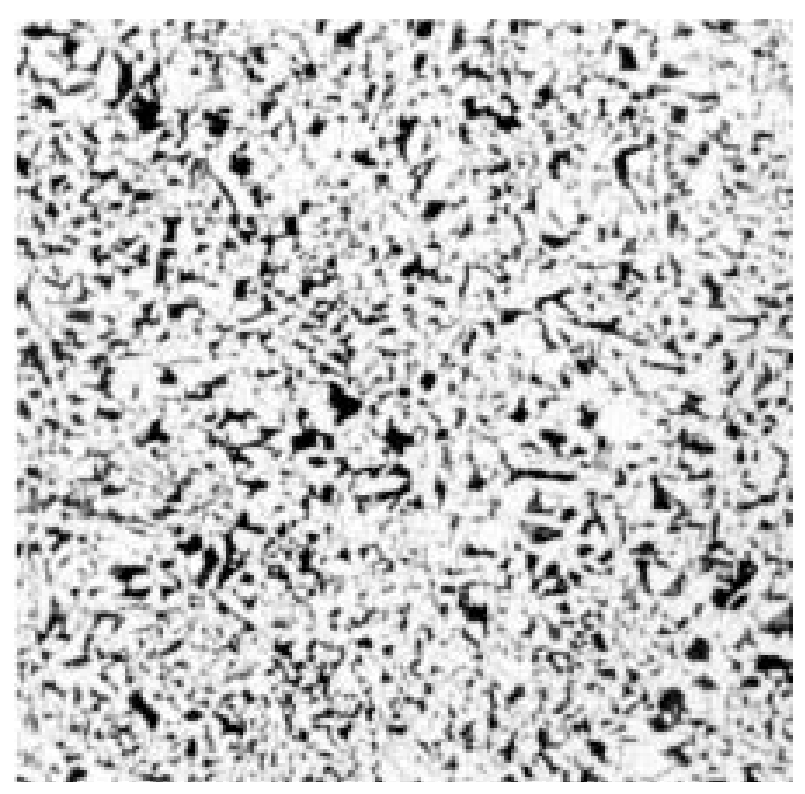

Fig. 17 Ferritic-pearlitic structure, a longitudinal section, 100x, etch. $3 \%$ NITAL

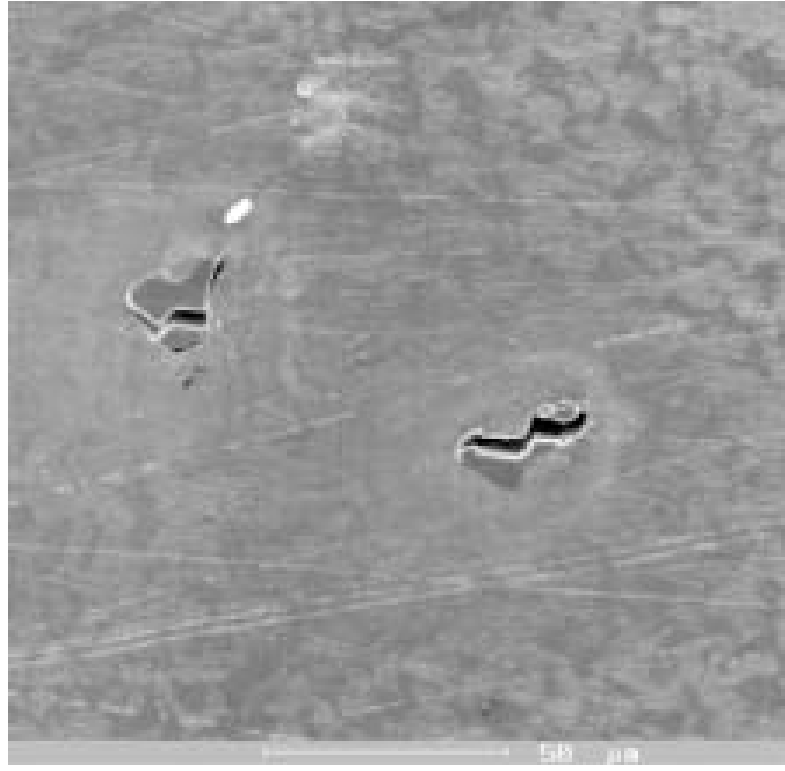

Fig. 16 Cracked inclusions on the surface of the testing rod, REM

(Figs. 19 and 20) and there are grains of a very small (6 $\mu \mathrm{m})$ size and of very large sizes $(45 \mu \mathrm{m})$.

Pearlite is of a lamellar character in some grains and globular in others. Sporadically, Widmannstättenic ferrit was observed in the areas with near by big grains. Except for very irregular grains, inclusions of various shapes and parameters occurred in the structure (Figs. 21 and 22), while they nearly always had a non-coherent interface. The separation of inclusions from the matrix is probably caused by a long-term dynamic loading with a relatively high amplitude (in the relation to fatigue properties of the evaluated steel).

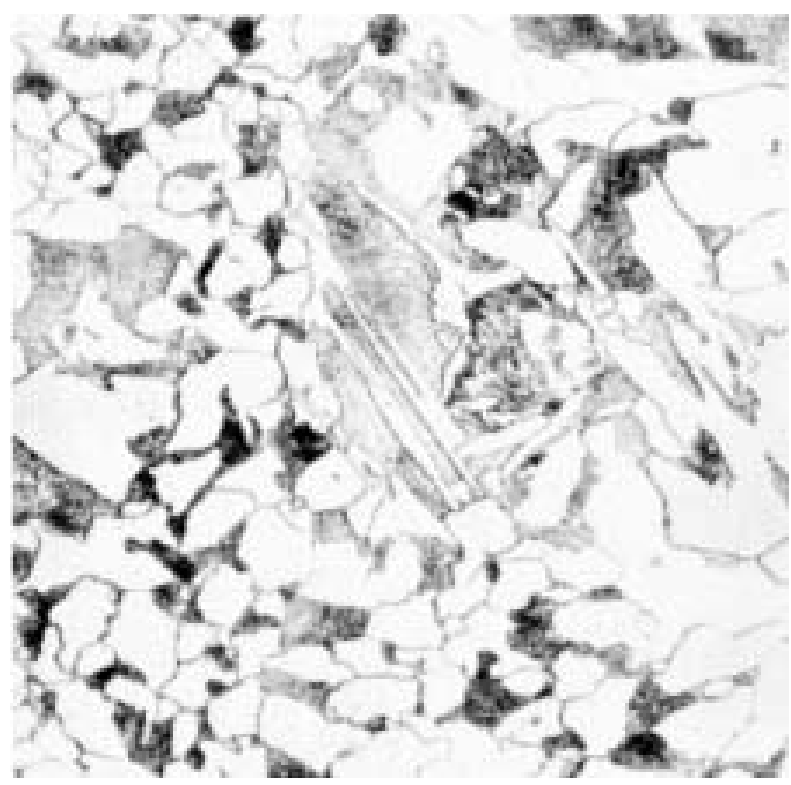

Fig. 18 Ferritic-pearlitic structure, a diagonal section, 400x, etch. 3\% NITAL 


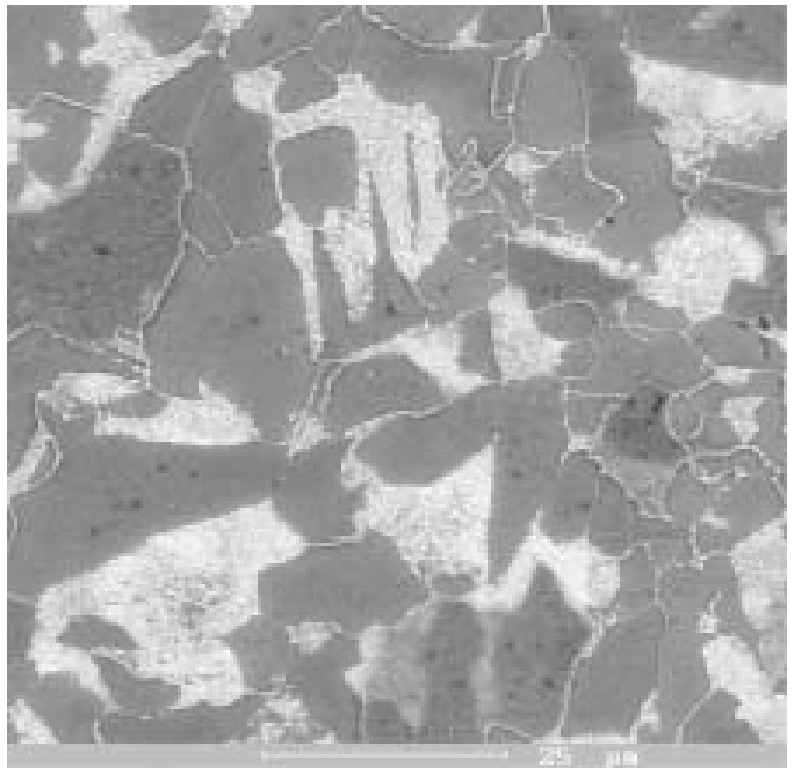

Fig. 19 Ferritic-pearlitic structure, a longitudinal section , REM

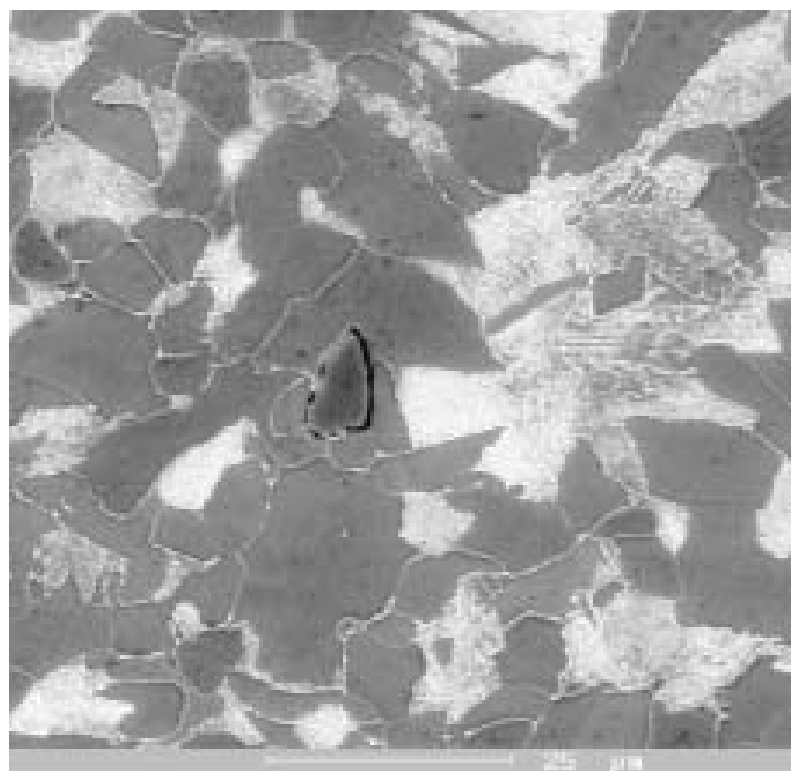

Fig. 21 The presence of an inclusion in the material structure, irregular size of grain, REM

\section{Fractographic evaluation}

The specimen for the fractographic evaluation was extracted in the way to record the place of a supposed beginning of the crack growth, its gradual progress to the final fracture (Figs. 23 to 28). There were two sources on the evaluated fracture area (Fig. 23) from where the crack began to grow. In Fig. 23 the source is on the surface, the second source is superficial (Fig. 24). Most probably there was a bigger inclusion that served as a crack nucleus. But we cannot confirm this as the fracture area is damaged by

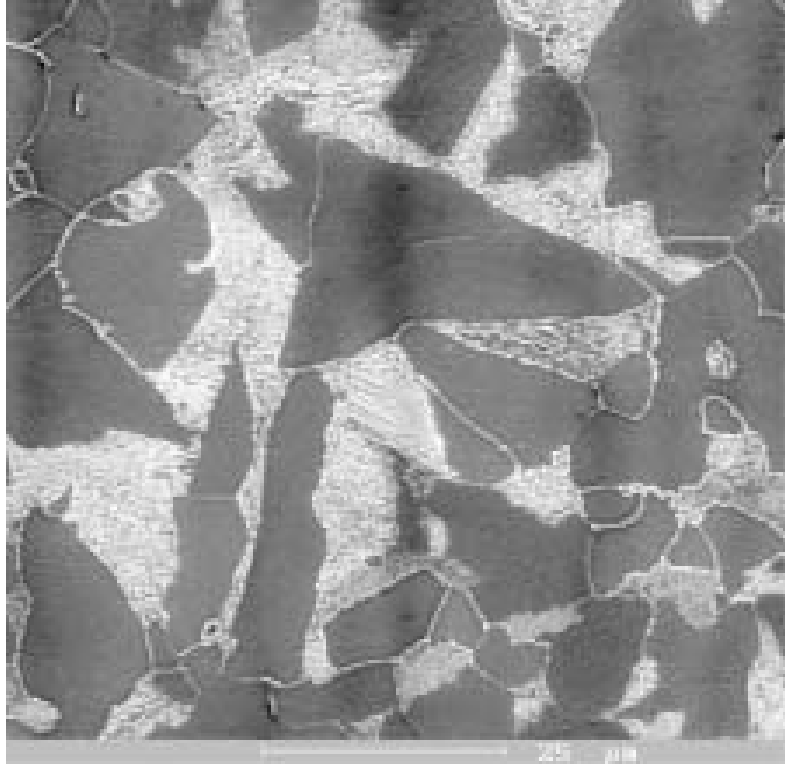

Fig. 20 Ferritic-pearlitic structure, a diagonal section, REM

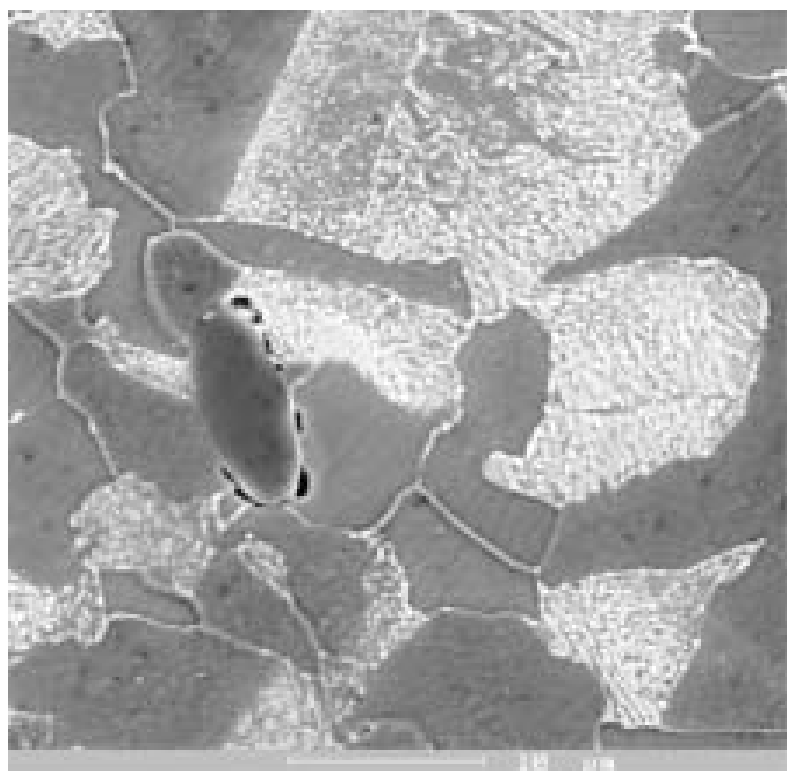

Fig. 22 The detail of ferritic-pearlitic structure with occurrence of an inclusion, REM

oxides and pressing on this particular place. The pressing and partial oxidation was observed on the whole fracture area.

The character of the fatigue fracture area in the direction from the source to the force fracture is shown in Figs. 25 and 26. The whole fatigue fracture is characteristics by a transcrystalline fatigue failure with the occurrence of relatively deep secondary cracks (Fig. 25). At bigger magnifications typical fatigue signs - striations were observed (Fig. 26). 


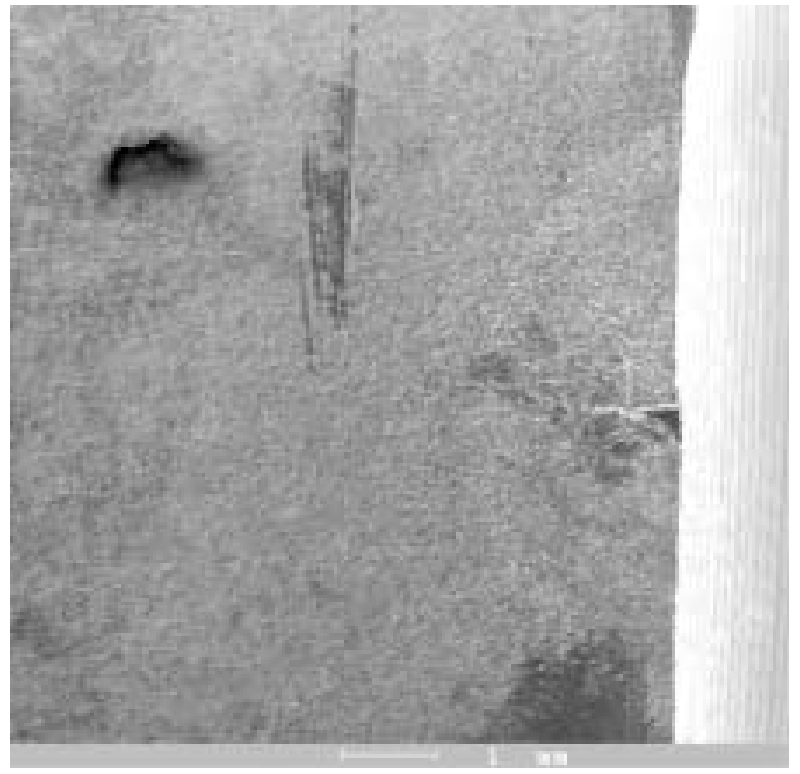

Fig. 23 The beginning of the crack growth - one of the sources, REM

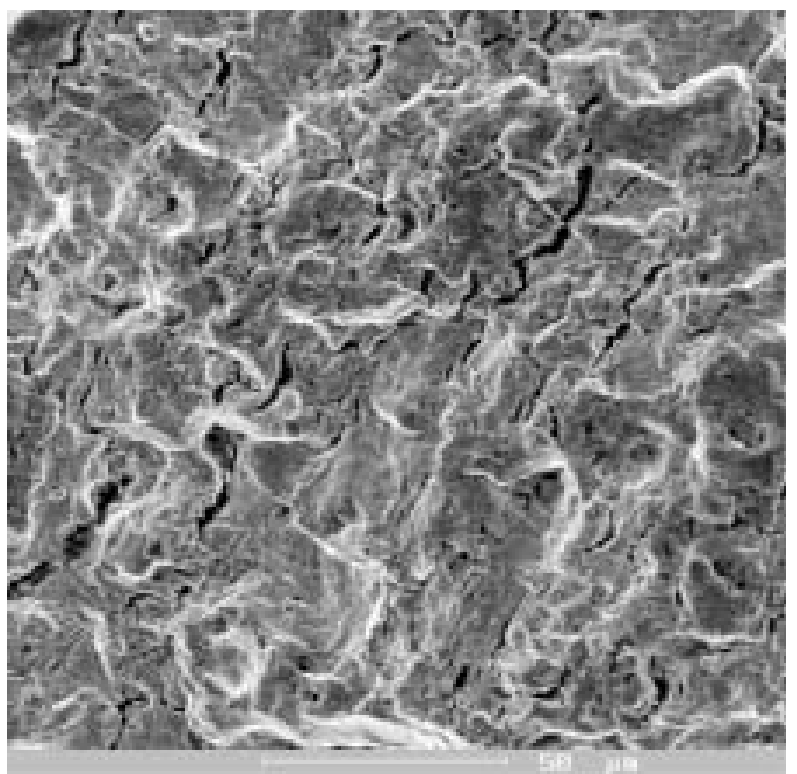

Fig. 25 The character of fatigue fracture area further from the source, REM

The area of fracture is characteristics with a transcrystalline ductile failure with dimple morphology (Figs. 27 and 28), while the dimples were very heterogeneous which is related to the material heterogeneity. Big dimples correspond to ferrit, small dimples are pearlitic.

\section{Conclusion}

From the manifestation of the failure and appearance of functional surfaces of individual parts of the rod and piston results

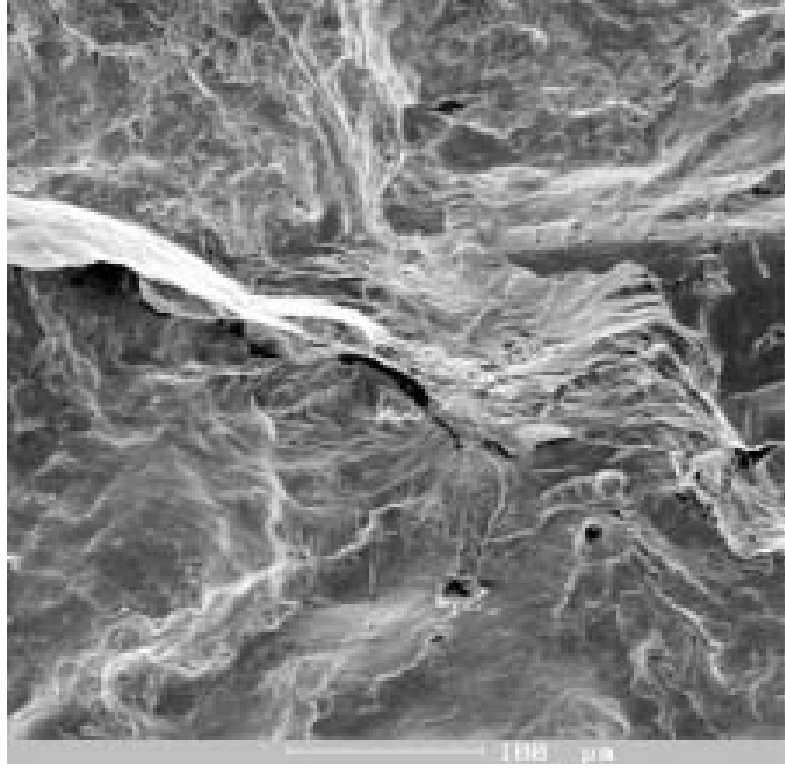

Fig. 24 The detail of a sub-surface source, REM

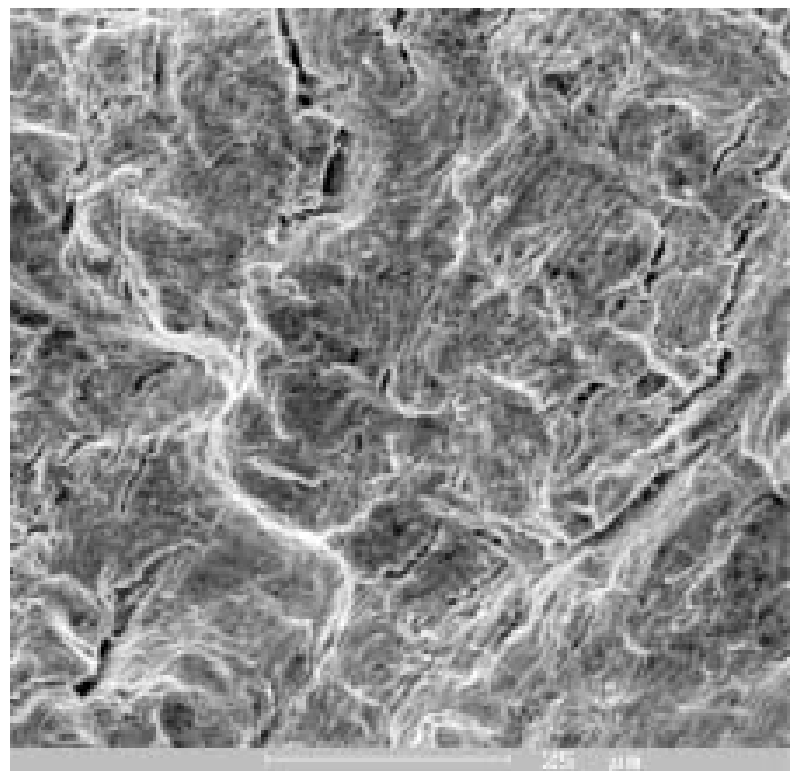

Fig. 26 A transcrystalline fatigue failure with the occurrence of striations and cracks, REM

that the rod was loaded by additional loading - probably by bending - that caused the failure of the functional areas of the rod and impeller wheel by contact fatigue. Apart from the above mentioned the rod has an unsatisfactory geometry of the gasket slot under the flange. The vanes of the impeller wheel had a mechanical contact with the turbine chamber. It means that the turbine did not have perfect bearings.

On the basis of the experimental evaluation of the state of the rod material from the impeller wheel of a TG2 turbine it is possible to state that according to the recorded chemical composition the 


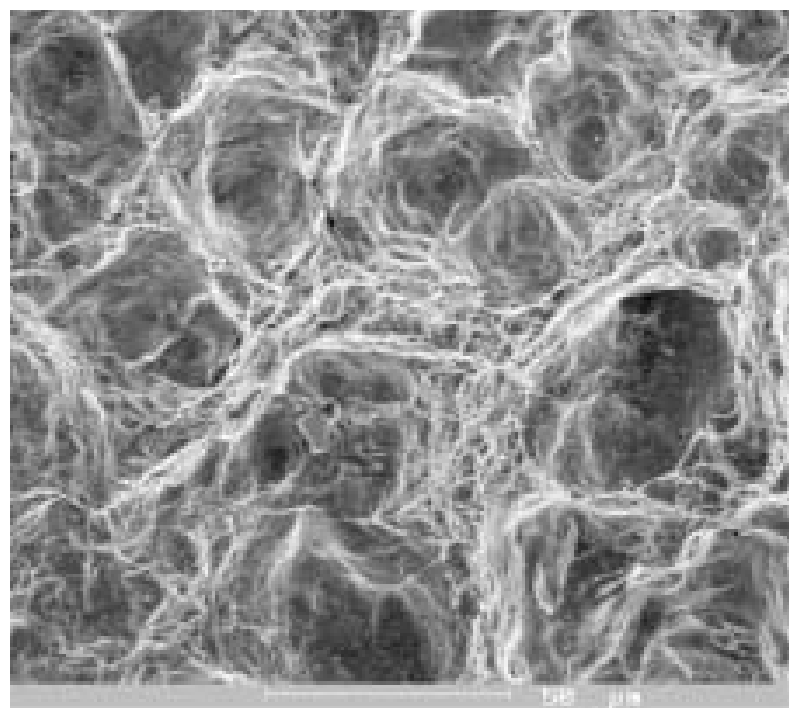

Fig. 27 The area of fracture, a transcrystalline ductile failure with dimple morphology, REM

rod material corresponds to the quality of StE 500 steel (Tab. 1), but its tensile strength reaches the values $R m=489 \mathrm{MPa}$ a $\mathrm{Re}=$ $317 \mathrm{MPa}$, i. e. by $100 \mathrm{MPa}$ lower than the norm for StE 500 steel. This is inaccessible for the use.

The metallographic evaluation shows that the microstructure of steel is irregular, ferritic-pearlitic created by grains of various sizes (Figs. 17 to 22) while pearlite is lamellar in many cases but it appears also in a spheroidized shape and in many cases in Widmannstätten structure. It results from these facts that the inadmissible state of the structure was caused by wrong the heat regime at the production. The inclusions occurring in the structure were separated from the basic material and they operated as the crack nuclei (Figs. 15 and 16). At mechanical loading, the cracks were created around the inclusions at the tension just over the yield stress.

The fatigue fracture started from several sources on the rod circumference which is related to the inconvenient structure and state

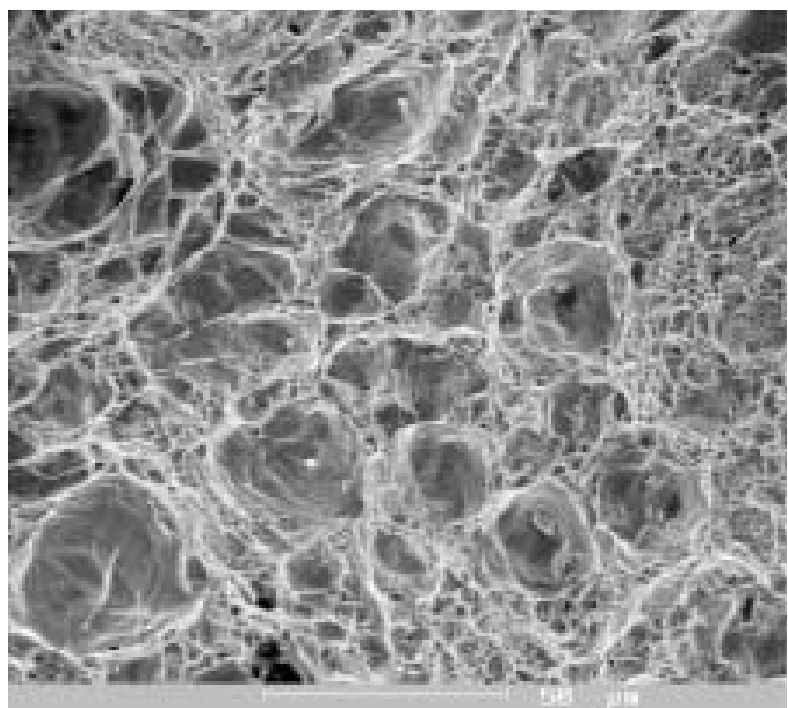

Fig. 28 The area of fracture - big dimples are ferritic, small are pearlitic, REM

of the material (Figs. 23 to 26). The fatigue fracture is characteristics by a transcrystalline fatigue failure with ductile and fragile striations (Figs. 25 and 26) while there are many secondary cracks on the fatigue fracture area. The area of force fracture is characterized by a transcrystalline ductile failure with dimple morphology while the dimples have a very distinct diameter (Figs. 27 and 28).

The individual findings lead to the following conclusions. The failure of the impeller wheel was cause by:

- a failure of the rod construction (high values of local tensions)

- a failure of material (strength characteristics lower by $20 \%$ than the norm)

- an mistakes at installation (vibrations and oscillation of the whole impeller wheel).

This work has been supported by the Scientific Grant Agency of the Ministry of Education of the Slovak Republic and Slovak Academy of Sciences, grant No. 1/3155/06

\section{References}

[1] SKOČOVSKÝ, P., BOKŮVKA, O., PALČEK, P.: Material Science (in Slovak), EDIS, ŽU Žilina, 1996.

[2] DRASTÍK, F. et al..: Atlas of Metal Applications in the Engineering, Electrical Engineering and Chemical Industry (in Czech), SNTL, Praha 1980.

[3] MITURA, K., LANDOVÁ, S.: Inclusions in the Steels (in Czech), SNTL Praha, Praha 1986

[4] SKOČOVSKÝ, P., PALČEK, P., KONEČNÁ, R., VÁRKOLY, L.: Structural Materials (in Slovak). EDIS ŽU Žilina, 2000.

[5] PLUHǍ̌, J., PUŠKÁR, A., KOUTSKÝ, J., MACEK, K., BENEŠ, V.: Physical Metallurgy and Threshold States of Materials (in Czech), SNTL/ALFA, Bratislava, 1987.

[6] KOUTSKÝ, J., JANDOŠ, F., KAREL,V.: Fracture of Steel Parts (in Czech), SNTL, Praha, 1976.

[7] JECH, J.: Heat Treatment of Steels (in Czech), SNTL Praha, 1983.

[8] PALČEK, P., HADZIMA, B., CHALUPOVÁ, M.: Material Properties (in Slovak). ŽU v Žiline, Žilina 2004.

[9] BOK(VKA, O., NICOLETTO, G., KUNZ, L., PALČEK, P., CHALUPOVÁ, M: Low and High - frequency fatigue testing. EDIS ŽU Žilina, October 2002. (ISBN 80-8070-011-7).

[10] PALČEK, P., CHALUPOVÁ, M., NICOLETTO, G., BOK(VKA, O.: Prediction of Machine Element Durability. Education Aid for Multimedia Lectures. ES ŽU Žilina, 2003. 